\title{
Psicologia da Arte: fundamentos e práticas para uma ação transformadora
}

\author{
Psychology of Art: Fundamentals and practices \\ for a transformative action
}

\author{
Vera Lúcia Trevisan de SOUZA ${ }^{1}$ iD) 0000-0003-2062-0680 \\ Lilian Aparecida Cruz DUGNANI' ${ }^{\text {ID }}$ 0000-0002-6888-6130 \\ Elaine de Cássia Gonçalves dos REIS ${ }^{\text {ID }}$ 0000-0001-5024-3017
}

\section{Resumo}

O presente artigo destaca a arte, em sua dimensão humanizadora e potencial para afetar o sujeito, como instrumento de trabalho do psicólogo no favorecimento da constituição de formas mais elaboradas de o sujeito ser, estar, pensar e agir no mundo. As proposições apresentadas se assentam nos conceitos de Vigotski, notadamente aqueles da "Psicologia da Arte", defendendo a potência dessa linguagem para fazer emergirem emoções, contradições e a reflexão, como meios de fazer avançar a consciência sobre si e sobre o mundo. Assumindo essa perspectiva, o artigo apresenta o relato de parte de uma pesquisa-intervenção realizada em uma escola da rede pública estadual de Ensino Fundamental II e Médio, com turmas do ensino médio noturno, focalizando a expressão de uma das estudantes, que elucida o caráter promissor da arte na promoção da imaginação de adolescentes.

Palavras-chave: Arte (Psicologia); Imaginação; Psicologia histórico-cultural; Psicologia educacional.

\begin{abstract}
This paper highlights art in its humanizing and potential dimensions to affect the subject. As a psychologist's instrument, it works in favor of the constitution of more elaborate forms of being, think and act in the world. The propositions presented are based on the concepts of Vygotsky, notably those from "Psychology of Art", in which the author defends

1 Pontifícia Universidade Católica de Campinas, Centro de Ciências da Vida, Programa de Pós-Graduação em Psicologia. Av. John Boyd Dunlop, s/n., 13060-904, Jd. Ipaussurama, Campinas, SP, Brasil. Correspondência para/Correspondence to: V.L.T. SOUZA. E-mail: <vera.trevisan@uol.com.br>.

Apoio: Coordenação de Aperfeiçoamento de Pessoal de Nível Superior (Processo nº 2016/163207-5).

$\boldsymbol{\nabla} \mathbf{\nabla} \boldsymbol{\nabla}$

Como citar este artigo/How to cite this article

Souza, V. L. T, Dugnani, L. A. C., \& Reis, E. C. G. (2018). Psicologia da Arte: fundamentos e práticas para uma ação transformadora. Estudos de Psicologia (Campinas), 35(4), 375-388. http://dx.doi.org/10.1590/1982-02752018000400005
\end{abstract}


the power of art to emerge emotions, contradictions, and reflection as means of developing consciousness about oneself and the world. This article reports part of an intervention-research carried, at a school of the state public network of elementary school II and middle whose expression of one of the students elucidates the promising character of art in promoting the imagination of adolescents.

Keywords: Art (Psychology); Imagination; Cultural-historical psychology; Psychology educational.

Este artigo destaca a arte em sua dimensão humanizadora e potencial para afetar o sujeito, como instrumento de trabalho do psicólogo, na mediação da constituição de formas mais elaboradas de ser, estar, pensar e agir no mundo. Como núcleo organizador das relações que se constroem e se mantêm nos espaços educativos, a arte favorece as ressignificações dos sujeitos sobre seu papel nas diferentes interações de que tomam parte e sobre suas condições de vida atual e futura. O espaço educativo, que assume primazia nas proposições ora apresentadas, é o da escola pública de educação básica, notadamente da rede estadual de ensino que atende adolescentes no Ensino Fundamental Il e no Ensino Médio.

Essas acepções se assentam nos pressupostos teórico-metodológicos da Psicologia Histórico-Cultural, sobretudo aqueles defendidos por Vigotski (1925/1999) em seu livro "Psicologia da Arte". O presente estudo assume características de pesquisa-intervenção, visando simultaneamente produzir conhecimentos sobre os fenômenos investigados, elaborar métodos para acessá-los e oferecer subsídios para o desenvolvimento de práticas psicológicas comprometidas com a transformação das condições que produzem alienação e sofrimento dos sujeitos que estudam e trabalham na escola.

Na cotidianidade, os modos de interação entre sujeito e realidade se constituem a partir de certo nível de consciência e de intencionalidade, em que um afeta e constitui o outro de maneira dialética e permanente. Entretanto, o ritmo da vida cotidiana é marcado pelo imediatismo e pela incompletude, não oferecendo possibilidades para questionamentos e reflexões. Na vida vivida, passado e presente imbricam-se indissociavelmente, e os sujeitos são chamados a comparecer por inteiro e a revelar a síntese histórica do desenvolvimento possível de sua personalidade até aquele dado momento, por meio da expressão, subsequente às afecções produzidas nessas relações, dos seus pensamentos, de suas emoções e de suas ações (Arendt, 1958/2014; Heller, 1989; Vigotski, 1934/2009).

As demandas da vida vivida estão na base dos motivos que levam os sujeitos a se relacionarem pragmaticamente com a realidade, e a orientarem sua conduta para atender rapidamente as reivindicações Ihes são apresentadas, fazendo emergir o olhar que padece de "viciação de origem" 2 como forma de significar o mundo. Nessas ocasiões, embora o olho veja situações heterogêneas, consegue enxergá-las apenas a partir de um único prisma, que as fragmenta e as homogeneíza, dando origem aos automatismos e cristalizações dos modos de perceber, explicar, relacionar-se e atuar em diferentes contextos. As condutas que decorrem dessas interações quase sempre carregam em si a possibilidade da não conclusão do desenvolvimento de formas mais elaboradas de relação da pessoa com o mundo, uma vez que estas não contribuem para a mobilização dos recursos humanos potenciais que poderiam levar à construção de formas mais criativas de se relacionar com a realidade e à transformação das próprias condições materiais de existência (Heller, 1989; Vigotski, 1934/2009).

\section{$\boldsymbol{\nabla} \mathbf{\nabla} \boldsymbol{\nabla}$}

$\mathbf{2}$ Termo utilizado por Guimarães Rosa, no conto "O Espelho", para se referir à cristalização do olhar em relação ao cotidiano. "E os próprios olhos, de cada um de nós, padecem de viciação de origem, defeitos com que cresceram e a que se afizeram, mais e mais. Por começo, a criancinha vê os objetos invertidos, daí seu desajeitado tactear; só a pouco e pouco é que consegue retificar, sobre a postura dos volumes externos, uma precária visão. Subsistem, porém, outras pechas, e mais graves. Os olhos, por enquanto, são a porta do engano; duvide deles, dos seus, não de mim. Ah, meu amigo, a espécie humana peleja para impor ao latejante mundo um pouco de rotina e lógica, mas algo ou alguém de tudo faz frincha para rir-se da gente... E então?" (Rosa, 1962/2001, p.95). 
A promoção de mudanças dessas condições, por sua vez, perpassa pelo favorecimento de vivências que tenham em sua base o humano-genérico e que se caracterizem pela quebra da direção da conduta da vida cotidiana (a qual se orienta pelo "eu") e pela constituição de formas de relação direcionadas ao "nós". Para isso, é preciso alterar o ritmo da e na vida vivida, por meio do estabelecimento de pausas que possibilitem ao sujeito exercitar seu olhar na busca do não aparente, a fim de desvelar os mistérios e as causas que fazem a realidade se apresentar tal como é. O humano-genérico não nega a cotidianidade, mas a incorpora em uma complexa rede que amalgama passado, presente e futuro, contrapondo, dialeticamente, o que se pôde ser efetivamente ao que se pode ser potencialmente, produzindo um tensionamento permanente entre o real e o ideal (Arendt, 1958/2016; Heller, 1989; Souza, 2016a; Vigotski, 1934/2009).

Esses movimentos não se deflagram naturalmente, mas são consciente e intencionalmente construídos nas e pelas relações, mediados pelas produções da cultura humana, que podem assumir a qualidade de instrumentos psicológicos que operam como signos mediadores, nos e dos processos de significação e ressignificação da realidade, favorecendo a reflexão da ordem do humano-genérico (Arendt, 1958/2014; Heller, 1989; Souza, 2016a; Vigotski, 1934/2009). As autoras do presente estudo vêm afirmando em suas produções escritas que não trabalham com a Arte enquanto área de conhecimento, com fins de ensino, o que é próprio da atividade dos educadores em Artes e dos artistas. Seu esforço tem sido empreendido na compreensão da Psicologia da Arte, no efeito que a Arte produz no outro, na produção do "comum" (Spinoza 1677/1989), do coletivo (Martín-Baró, 1997; Petrovski, 1984) e do "nós" (Heller, 1989), bem como no entendimento de seu papel na constituição de um contexto educativo que promova o desenvolvimento de formas mais elaboradas de relações (Dugnani \& Souza, 2016; Petroni \& Souza, 2014; Souza, 1998; Souza, 2016a; Souza, Dugnani, Babosa, Jesus, \& Neves, 2016).
Entretanto, é preciso declarar que essas acepções aqui propostas, do lugar que a arte pode assumir na pesquisa-intervenção, têm demandado estudos e reflexões permanentes do grupo, conduzindo-o a buscar diferentes teóricos de variadas áreas de conhecimento, no movimento de sustentar o que Vigotski (1925/1999) anuncia em seu livro "Psicologia da Arte". Dentre tais teóricos, destacam-se Ernest Cassirer, filósofo que estuda o desenvolvimento do símbolo como dimensão central da constituição do pensamento humano; sua discípula Suzanne Langer, com suas contribuições para a compreensão da significação de formas de arte e de discurso; o pintor Kandinsky (2015, p.27), para quem "toda obra de arte é filha de seu tempo e, muitas vezes, mãe dos nossos sentimentos"; o crítico de arte e artista plástico Ferreira Gullar, cuja apreciação do conjunto da arte produzida pela humanidade e da arte contemporânea guiou e guia o olhar das autoras deste ensaio, ensinando-as a ver; e Jorge Coli, emérito professor e mestre das artes contemporâneo, que ilumina a compreensão sobre as materialidades artísticas com seus ensinamentos da História e da Cultura. Há ainda o campo da semiótica, visitado e perscrutado em busca da compreensão da teoria dos signos e significações, por vezes mediados pela produção do professor Angel Pino, que também deixou importante legado de sua compreensão acerca da teoria de Vigotski.

O que se quer revelar, com essas citações de conhecimentos e autores, é que empreender a defesa da Psicologia da Arte como instrumento psicológico que promove poder de agir nos sujeitos, justamente por seu potencial de fazer emergir as emoções, sua compreensão e favorecer o acesso à dimensão do humano-genérico, demanda muito estudo e diálogos infinitos e permanentes com outros campos do conhecimento, sobretudo a Filosofia, a História da Arte, a Semiótica, a Estética e a crítica em arte. E, obviamente, demanda que o analista se embrenhe no mundo da produção artística como apreciador, de modo a viver as afecções que a obra produz no ser humano, que vive a vida cotidiana e busca "respiros" como momentos de assunção a um olhar que olha além do que se vê. 
É essa a perspectiva e pressuposto assumidos neste artigo, em que se apresentam algumas experiências de pesquisa-intervenção que têm revelado esse caráter promissor da Psicologia da Arte: por um lado, como mediação potente da conscientização e ressignificação da realidade e, por outro, como promotora da imaginação que faz emergirem e se consolidarem processos criadores valiosos ao desenvolvimento de adolescentes que passam a se projetar no futuro.

Inicialmente, apresentam-se alguns fundamentos da Psicologia da Arte, que têm sustentado as investigações das autoras deste estudo. Em seguida, apresenta-se o método utilizado para a compreensão dos fenômenos investigados, com destaque ao que aqui se denomina pesquisa-intervenção; subsequentemente há um eixo de análise de parte dos resultados de uma das pesquisas do grupo, que investiga o potencial da arte na construção de novas perspectivas de futuro de adolescentes do Ensino Médio noturno que frequentam uma escola pública de periferia de uma grande cidade. O artigo termina com a apresentação de uma síntese provisória de formulações sobre a Psicologia da Arte na ação do psicólogo escolar de perspectiva crítica.

\section{Imaginação e emoção na promoção do desenvolvimento do psiquismo: aportes da Psicologia da Arte}

Compreendida como uma linguagem que tem sua gênese nas relações sociais e que apresenta como peculiaridade a potência de afetar os sujeitos pela via do sensível, a obra artística, por apresentar conteúdos e formas da cultura, por um lado, e por seu caráter aberto, por outro, pode promover o estranhamento da realidade, que é condição essencial para a atribuição de novos significados e sentidos em relação ao vivido (Dugnani \& Souza, 2016; Petroni \& Souza, 2014; Souza, 1998; Souza, 2016a; Souza, Dugnani, Petroni, \& Andrada, 2015).
O desenvolvimento de formas mais complexas de relação do sujeito com o mundo está condicionado às mediações que são favorecidas por suas relações concretas com a realidade. Este ensaio defende que a relação com a obra de arte pode promover esse movimento, visto que a apreciação estética pode se configurar como uma atividade mediatizada e mediatizante.

É mediatizada porque, ao ser utilizada pelo psicólogo intencionalmente, como narrativa que expressa a síntese histórica dos sentimentos/espírito de uma época em relação a um determinando fenômeno ou evento, atua a um só tempo sobre o "eu" e sobre o "outro". Favorece a dialogia, por meio do compartilhamento das emoções, pensamentos e ações que decorrem das afecções produzidas pela apreciação artística da obra, e que assumem a qualidade de signo emocional comum ${ }^{3}$, mediando a construção coletiva dos processos de ressignificação do cotidiano (Friedrich, 2018; Vigotski, 1925/1999).

E é mediatizante porque pode conferir novas qualidades às funções psicológicas superiores, por meio do desenvolvimento de formas mais complexas, criativas e autorais de se compreender e atuar a "partir de" e sobre a realidade, alterando o curso e a direção da constituição dos motivos que orientam a conduta, direcionando-os para a superação e transformação coletiva das condições materiais de existência (Andrada \& Souza, 2015; Friedrich, 2018; Souza, 2016a).

Dugnani $(2017$, p.6) afirma que é com "o advento da arte moderna e o desenvolvimento do abstracionismo, no início do século $X X "$ que os estudos sobre o desenvolvimento da estética humana passam a se debruçar sobre uma questão fundamental: a relação entre a arte e a plasticidade dos processos de significação que dela decorrem. Por sua linguagem singular e basicamente representativa, as obras artísticas dos mais variados segmentos podem promover, a um só tempo, uma aproximação e um afastamento entre a forma e o

Souza (2018) definem signo emocional comum como "uma combinação de imagens e eventos que possuem uma mesma base afetiva”. As autoras destacam que, para exemplificar essa ideia, Vigotsky (1930/2009) dá como exemplo as significações histórica e culturalmente atribuídas às cores: "el hombre simboliza com el color negra al dor y al luto; com el branco a la alegria ..." (p.10). 
conteúdo, entre o significado e o sentido, entre o verbal e o icônico. E é essa qualidade da obra de arte que Vigotsky (1930/2009) considera essencial para o desenvolvimento da Psicologia da Arte e para o desvelamento de seu problema central: a compreensão do elo entre a imaginação e a emoção na promoção do desenvolvimento humano.

O desenvolvimento de formas mais complexas do psiquismo condiciona-se à apreensão da totalidade que constitui a vida e demanda o conhecimento das contradições que a constituem. Nas inserções nas escolas, é comum ouvir de professores que os alunos não estudam porque a família não apoia; dos gestores, que a escola não se transforma porque os professores são resistentes às mudanças; e, dos alunos, que eles não estudam porque os colegas são muito bagunceiros. Pois bem, se se pensar que o desenvolvimento da consciência decorre da relação dialética entre o sujeito e a realidade, em que o primeiro comparece com as suas crenças, valores e experiências, construindo as formas de perceber a si, aos outros e ao mundo, pode-se afirmar que essas expressões dos sujeitos reais revelam a consciência dos alunos e dos educadores em relação à escola que têm, e também a mediação, enquanto núcleos organizadores das relações nesses espaços, que se orientam pela responsabilização do outro (Andrada \& Souza, 2015; Petroni \& Souza, 2014; Souza, 2016a).

A responsabilização do outro é constantemente apontada pela literatura como uma forma de manutenção da alienação (Charlot, 2013; Dugnani \& Souza, 2016; Placco \& Souza, 2012). Isso leva a se questionar se, no caso do exemplo citado, os educadores e os alunos estariam irremediavelmente alienados, cabendo a uma ação externa "corrigir" sua visão e "trazer luz" à sua consciência. Pensa-se que não, visto que as leituras que fazem de sua realidade, de fato, descrevem as situações que se repetem constante e cotidianamente. É fato que os professores muitas vezes não contam com o apoio dos pais, como o é que muitas salas são desorganizadas e que os alunos agitados dificultam a concentração daqueles que querem prestar atenção na aula, assim como também é fato que os gestores realmente enfrentam resistências quando propõem algum novo projeto aos professores. E, de modo contraditório, evidencia-se, nesses exemplos, que os sujeitos têm consciência das condições que vivenciam em seu dia a dia.

Mas essa é uma consciência constituída no e pelo cotidiano, tomando a realidade a partir do que é, do que está explícito. E como tal se configura com as especificidades da cotidianidade - a fragmentação, a tendência à reprodução de visões moralizantes, naturalizantes e patologizantes, e a busca pela harmonização entre forma e conteúdo na construção de explicações da vida vivida. Compreender as relações, dessa perspectiva, implica considerar os pontos de vista dos educadores e dos alunos como sujeitos reais e históricos, que vivenciam e configuram esse contexto tal como ele se apresenta, e esse deve ser, portanto, o ponto de partida para qualquer ação que se pretenda realizar.

É preciso considerar também que as emoções, como constitutivas das significações que se produzem nas relações empreendidas nas práticas cotidianas, à semelhança do que ocorre com as ações e com os pensamentos, se automatizam e se cristalizam. Nessas ocasiões, a emoção pode se tornar "senhora" e assumir prevalência na mediação dos modos de relação do sujeito com a realidade, impedindo a reflexão, que é a condição primordial para a superação das paixões que levam os sujeitos a padecerem (Spinoza, 1677/1989).

Spinoza (1677/1989) afirma que uma substância só pode ser transformada por outra substância da mesma natureza e que cause uma afecção maior do que a primeira. Isso permite considerar que, se são os afetos, na qualidade de emoções e sentimentos cristalizados que estão na base da rigidez dos modos de relação na escola, a utilização de instrumentos mediadores que os coloquem em movimento e possibilitem a sua expressão pode promover a sua transformação. E, como afirmado, a arte tem se mostrado potente na promoção dessas afecções e no favorecimento da ampliação da consciência dos sujeitos em relação à realidade em que estão inseridos.

Compreende-se por ampliação de consciência o desenvolvimento de modos ativos e criativos de o sujeito se relacionar com a realidade, 
de sua implicação na produção de mudanças, no reconhecimento de suas possibilidades e limites, na ação intencional de compreender-se e inserir-se na busca do coletivo como meio de obter a força necessária para transformação de suas condições de vida atual e futura. Trata-se, portanto, de colocar os afetos em movimento, de modo a se produzir "poder de agir" (Spinoza, 1677/1989).

Radica nessas proposições a intencionalidade na apropriação da arte como instrumento de intervenção pelo psicólogo escolar que assume a perspectiva crítica: não se trata de levar uma materialidade artística, como um filme, música ou pintura, mas de mergulhar, junto com a audiência, nos intrincados e infindáveis significados e sentidos expressos pelas formas de arte, em um movimento de apreciação que sente, perscruta, investiga e configura novos sentidos em relação ao que se sente e se vive na experiência com a obra. Ou seja, a obra de arte escolhida deve afetar os sujeitos em relação - pesquisador/psicólogo e os educadores/alunos - de modo a romper com a lógica do cotidiano da ação encadeada ao fato, e produzir estranheza, que impacta pelo sentir do desconhecido. E, a partir desse lugar de estranhamento, a imaginação é mobilizada para que novas compreensões sejam possíveis, no âmbito da emoção, do sentido e da significação, e do percebido/compreendido.

É possível afirmar que a obra de arte, para atuar como instrumento psicológico, precisa confundir, paralisar, dificultar a percepção da realidade, produzir estranhamento. Deve também fazer emergir as emoções contraditórias, dificultando a atribuição de significados e a configuração de sentidos, colocando o sujeito em um estado de contemplação e reflexão. A vivência da contradição é o que promove novas significações, superando a condição anterior de sentimento e pensamento, para, incorporando-os, construir novos nexos ou relações e ampliar a compreensão da realidade.

Para Vigotski (1925/1999), a contemplação é um processo ativo; trata-se do momento em que o psiquismo entra em uma espécie de "curto-circuito" e, por consequência, inicia uma intensa atividade. O estado de contemplação não revela falta de atividade, mas, ao contrário, uma ação que tem em sua base um esforço empreendido pelo sujeito para ressignificar as emoções e pensamentos (que até então não tinham sido nele despertados) a partir da contradição que emergiu pela apreciação estética. Nesse processo, a emoção passa a se servir da imaginação, para representar, em imagens, os afetos, sendo portanto vivida duas vezes, e por isso chamada de coemoção. A coemoção é o elo primordial entre a imaginação e a emoção, porque permite ao sujeito ampliar suas vivências. Ao entrar em contato com as narrativas das obras de arte, o seu repertório se amplia, porque pode experienciar algo para além de sua vida vivida, no âmbito do humano-genérico.

Esse movimento entre emoção e significação mediado pela imaginação, que é produzido pela contemplação de uma obra de arte, promove a transformação da intensidade, da frequência e da expressão das emoções, possibilitando sua ressignificação e, em decorrência, sua transformação. A compreensão desse processo permite acesso aos motivos que estão na base das ações e pensamentos do sujeito, possibilitando intervenções que visem à transformação de seu modo de viver a realidade atual (March \& Fleer, 2017; Vygotski, 1931/1995).

O sujeito não deixa de viver a emoção, e esta não deixa de ser constitutiva de seu psiquismo, mas pode "vivê-la a prazo" (Clot, 2014), de modo contemplativo, significado, e não de forma fragmentada e reativa. Vigotski (1925/1999) chama a atenção para o fato de que em muito difere a intensidade e expressão de uma emoção que decorre da experiência cotidiana daquela que é deflagrada pela apreciação estética. Nas palavras de Vigotski (1925/1999, p.269) "não sofro com alguém, mas sofro porque o sofrimento do outro gera motivos para que eu coloque em movimento o meu próprio sofrimento". Ambas as emoções são reais e concretas, a minha e a do personagem da obra: a minha vive em mim, e a do personagem da obra eu faço viver na apreciação estética e, ao mesmo tempo, a emoção nela expressa põe a minha em movimento. Então, a obra de arte e sua apreciação não produz emoção no sujeito que se empreende em sua leitura, mas faz a emoção 
que está nele viver, movimentar-se, tirando-a de um estado estático e fazendo-a migrar para novos modos de vida.

Para Vigotski (1925/1999), é pela potência de colocar o sujeito em estado contemplativo que a vivência estética, ao incorporar e transcender a vivência cotidiana, promove o desenvolvimento de formas mais complexas de relação com o mundo, possibilitando o desenvolvimento de ações dirigidas à transformação de sua realidade. Alguns desses movimentos são apresentados no ensaio de análise desenvolvido mais adiante.

\section{Método}

O método utilizado para as investigações e ações que tomam por base os conceitos desenvolvidos nos itens precedentes sustenta-se nos pressupostos teórico-metodológicos da Psicologia Histórico-Cultural, notadamente nas concepções de Lev S. Vigotski. A pesquisa aqui desenvolvida é de natureza qualitativa, com características de pesquisa participativa, a que se denomina de pesquisa-intervenção. A intervenção é, a princípio, uma forma de acessar a realidade investigada e promover ações que permitam pôr o fenômeno em movimento. Entretanto, ao afetar o fenômeno que se modifica pelo fato mesmo de ser afetado, a intervenção põe em questão a investigação, transformando a própria pesquisa em vários e diversos níveis e dimensões - desde os acercamentos possíveis do fenômeno, até os objetivos a serem investigados. Esse processo ocorre permanentemente, em uma relação dialética que ora evidencia a intervenção, ora a pesquisa, instituindo o caráter interdependente que a ambas assumem nesta abordagem. Essa interpendência, ao se constituir como tal, assume dimensões contraditórias que só se revelam no ato mesmo de pesquisar-intervir.

É unidade, uma vez que as ações de pesquisar e intervir são concomitantemente contraditórias e complementares, constituindo um processo em que ora a intervenção assume prevalência, quando a pesquisa sustenta as ações interventivas, e ora a pesquisa se constitui direcionadora das ações e a intervenção configura-se como condição ao seu desenvolvimento. A pesquisa-intervenção rompe com o papel de observador do pesquisador, que se envolve no processo de significação produzido no contexto, configurando novos sentidos em relação ao que significa agir e investigar os contextos de desenvolvimento. É possível assumir, dessa perspectiva, que o método constitui-se a um só tempo como caminho e produto da pesquisa (Vygotski, 1927/1991).

\section{Participantes}

O estudo, objeto da análise apresentada, foi desenvolvido com estudantes de duas turmas do $2^{\circ}$ ano do Ensino Médio noturno, totalizando setenta jovens com idade entre 16 e 18 anos.

\section{Lócus}

O estudo foi realizado em uma escola pública da rede estadual de Ensino Fundamental II e Médio, localizada na periferia de uma grande cidade do interior de São Paulo.

\section{Procedimentos}

As informações foram construídas a partir de 16 encontros, realizados no decorrer dos dois semestres letivos do ano de 2017. Os oito encontros iniciais visaram promover a reflexão dos jovens sobre trabalho e futuro, e para isso foram utilizadas materialidades artísticas, tais como músicas, documentários, fotografias e reproduções de obras de arte, assim como perguntas disparadoras para favorecer os processos reflexivos. Os oito encontros

\footnotetext{
${ }^{4}$ A grafia do nome do autor aparece de diferentes formas nas produções brasileiras e estrangeiras. A depender das traduções do russo, ora seu sobrenome é grafado com dois yy - Vygotsky, ora com um no início - Vygotski ou no fim - Vigotsky e, por último, com dois ii - Vigotski. No Brasil, após um período em que se discutiu sobre qual deveria ser a grafia correta, a maioria dos estudiosos do autor tem adotado esta última grafia - Vigotski - e mantido nas citações a forma como aparece nas obras utilizadas. É esta a razão de mantermos nos títulos e nos artigos deste tema as grafias utilizadas pelos autores.
} 
subsequentes tiveram o intuito de ampliar as informações sobre as profissões que despertavam o interesse dos alunos. Para a identificação das mesmas, foi realizado um levantamento, em sala de aula, sobre quais eram as carreiras que mais os atraíam, e, a partir do resultado, foram programadas palestras com os seguintes profissionais: médico, ator, jornalista, psicóloga, médica veterinária e piloto de avião.

Para este artigo, destacam-se a quarta e a quinta intervenção. No quarto encontro os estudantes assistiram ao vídeo da palestra do fotógrafo Sebastião Salgado intitulada "O drama silencioso da fotografia" e, após, realizaram a apreciação de retratos, apresentados em PowerPoint, bem como a leitura das imagens escolhidas. Com o intuito de favorecer a dialogia e a reflexão sobre o tema proposto, foram realizadas perguntas disparadoras, tais como: "O que vocês veem?" e "Como se sentem diante destas imagens?". Em seguida, foi proposta, aos estudantes, a produção de uma história a partir da escolha de uma ou mais imagens que os tivessem impactado.

Na quinta intervenção, foram realizadas a apreciação e leitura de imagens de reproduções de algumas obras de Escher. Para isso foram utilizadas impressões coloridas das obras, em papel A4 e plastificadas, que compõem o acervo do grupo de pesquisa. A leitura de imagens foi mediada pela pergunta "Quais sentimentos, pensamentos e relações você estabelece a partir do contato com essas obras?". Em seguida foi sugerida a produção de um texto ou de um desenho inspirado nas obras e nas discussões realizadas. A seguir apresentam-se detalhadamente as intervenções, os resultados e as discussões sobre esse processo.

\section{Resultados e Discussão}

\section{$\mathrm{O}$ que a arte tem de psicologia? A vivência de Alice}

O texto a seguir resulta de uma intervenção, em que foi realizada uma palestra sobre Sebastião Salgado, fotógrafo brasileiro premiado e conhecido mundialmente por retratar o ser humano nas mais variadas condições sociais, sobretudo de sofrimento. Após a exibição de um documentário sobre a biografia de Salgado (1996, 1997, 1999, 2000, 2007, 2013), foram apresentadas fotografias selecionadas de alguns de seus projetos, tais como Trabalhadores de 1996, Terra de 1997, Outras Américas de 1999, Êxodos de 2000, África de 2007 e Gênesis de $2013^{5}$.

Um dos objetivos era promover a reflexão e o diálogo sobre os temas que apareciam nas fotos - no caso das primeiras, acessar as formas de trabalho, sobretudo de exploração do trabalhador; no caso das demais, tomar contato com as condições de vida de realidades distantes da vivida no Brasil, mas nem por isso menos duras e perversas; e, no caso do último projeto, Gênesis, pensar sobre as possibilidades de superação dos problemas retratados nos projetos anteriores pelo próprio fotógrafo, contrapondo os limites e as possibilidades. Entendia-se que essa ação promoveria a agilização da imaginação pelo acesso a realidades distantes e a consequente ampliação da consciência dos jovens sobre os temas discutidos. Foi proposto, logo após a apresentação das imagens e discussão, que cada aluno escolhesse uma ou mais das fotografias apresentadas e escrevesse uma história a partir dela.

\footnotetext{
5 Projeto Outras Américas (1977-1984; publicado em 1999); Equador; Projetos Trabalhadores (1986-1991, publicado em 1996) - trabalhadores em uma mina de carvão na Índia; Projeto Terra (1980-1996, publicado em 1997) - bebês, abandonados e/ou confiados por suas famílias a uma instituição assistencial do Estado, tomando sol no telhado da FEBEM; Movimento Sem Terra iniciando um acampamento; Menino sem Terra; Garota estudando na escola do assentamento dos sem terra; Nordestina e Nordestino; Pai preparando o enterro de seu filho; Projeto Êxodos (1993-1999, publicado em 2000) - nordestinos migrando para as cidades grandes; Projeto África (2000-2003, publicado em 2007) - Garoto perdido de sua família após o massacre em Ruanda; Campo de refugiados de Ruanda; Projeto Gênesis (2004-2013; publicado em 2013) - Grupo de nômades na Sibéria; Elefantes, Pinguins nas Ilhas Sanduíche do Sul, na Antártida; Bushmen - Botsuana - Povos que vivem como há cinquenta mil anos atrás; Sítio que era da família de Sebastião Salgado no Brasil.
} 
A produção de uma das alunas, aqui nomeada como Alice, despertou a atenção das pesquisadoras: ela se colocara no lugar do fotógrafo e produzira uma síntese de todas as cenas retratadas por ele, carregada de emoção e muita criatividade. De modo semelhante, também se sobressai na atividade seguinte, com a apresentação de gravuras do artista gráfico holandês Maurits Cornelis Escher retratando obras fantásticas (Escher, 1938, 1953, 1960). É sobre essa produção e as interpretações das pesquisadoras que versa o próximo tópico.

\section{A vivência de Alice - múltiplos olhares agilizados pela imaginação}

Todo retrato é, em certo sentido, um autorretrato que reflete o espectador. Como o olho não se contenta em ver, atribuímos a um retrato as nossas percepções e a nossa experiência. Na alquimia do ato criativo, todo retrato é um espelho (Manguel, 2001, p.77).

É sobre a relação espectador/obra de arte que trata o texto de Alice que, ao colocar-se no lugar do fotógrafo, mergulha em seu universo e se entrega à vivência estética:

Ouvigritos de gente desesperada, implorando pela vida, ouvi choros escandalosos de crianças inocentes vendo seus pais sendo mortos, olhei a câmera e pensei que tudo que eu tinha estava ali, tudo o que eu podia fazer por aquela atrocidade estava ali a um click de distância, a distância entre a vida e a morte estava a um segundo, no click do botão e no desbanhar da espada. Senti o frio abraço da morte em meu corpo pálido causado pelo medo, senti o sangue saindo pelas minhas vísceras, tive medo, medo de morrer sem ter feito o suficiente, vi a luta de animais da mesma espécie, a humana, a minha espécie. Todo aquele holocausto estava vivo em mim, passei por terrores noturnos, pensei no rio de sangue no chão e o cheiro do massacre a inocentes, com gosto de egoísmo humano pelo poder na porta de meu alojamento, e tudo que eu tinha era uma fria câmera. Achei que morreria, mas superei um holocausto insuportável. Eu sobrevivi ao medo e eu estou aqui. Mais triste, porém mais forte (Alice, 15 anos, $2^{\circ}$ ano noturno).

A estética mostrada pela fotografia é a estética da vida, vida vivida por seres humanos, semelhantes ao espectador (será?). Nas intervenções com leitura de imagens, a fotografia, justamente por essa característica, produz grande impacto nos sujeitos que se empreendem na apreciação, revelando o potencial que a arte tem para tocar os afetos, para desencadear emoções e reflexões. Será que o retrato pode mesmo refletir o apreciador? Que reflexos de Alice teriam sido projetados nas fotografias de imigrantes deslocando-se, de massacres em Ruanda, de trabalhadores nordestinos em luta pela terra, de bebês abandonados em São Paulo, da miséria humana em lugares distantes - de humanos, de animais, de paisagens belíssimas, que inspiram a vida? Será reflexo ou refracção? Será espelho ou prisma, enquanto modo singular de se relacionar com o mundo?

Levando em consideração as reflexões de Manguel (2001), ensaísta e romancista argentino radicado no Canadá, para quem o público não especializado tem o direito de acessar a arte e ler imagens como quem lê palavras, "cada obra de arte se expande mediante incontáveis camadas de leituras, e cada leitor remove essas camadas a fim de ter acesso à obra nos termos do próprio leitor. Nessa última (e primeira) leitura, nós estamos sós" (p.32). Evidencia-se a dimensão dialética contida na estética da obra de arte: "A linguagem humana é feita de palavras que se traduzem em imagens e de imagens que se traduzem em palavras - ambas são matéria de que somos formados" (p.350).

Parece ter sido esse movimento que Alice faz - das imagens para a palavra. Mobilizada pela estética própria da fotografia, produz um texto crítico, cuja emoção está no centro, expressa pela indignação em relação às cenas acessadas. As realidades, ainda que distantes de sua experiência, são vividas com emoções reais. Eis uma das dimensões da imaginação e seu enlace emocional, conforme postula Sawaia (2009). 
As palavras produzidas por Alice, articuladas em um texto com contornos poéticos, cria outras imagens no leitor apreciador de seu texto - no caso das autoras, a imagem de uma jovem com grande potencial para superar a desigualdade que caracteriza suas condições de vida, e a imagem de uma escola que pode se constituir como Situação Social de Desenvolvimento ${ }^{6}$ e promover consciência enquanto novos modos de pensar e agir. Uma escola capaz de produzir devires, para além dos horizontes já desenhados e mesmo tramados para o jovem de escola pública noturna de periferia das grandes cidades.

Há um aspecto da atividade de intervenção que potencializou a imaginação de Alice e seu processo de criação do texto: a proposta de colocar-se no lugar de um personagem, de imaginar-se naquele cenário. $\mathrm{E}$, por características singulares, constituídas em suas experiências, Alice incorpora o personagem principal - o fotógrafo - e então exercita um olhar, uma relação, um ponto de vista, uma emoção, até então impensada, não imaginada ou vivida, e confere novas camadas às fotografias. Cabe aos leitores do Salgado e agora de Alice, removê-las.

As autoras deste estudo reconhecem que, embora apreciadoras do artista, nunca se colocaram em seu lugar nem se imaginaram na cena, com seus conflitos. Passaram ao largo do sujeito fotógrafo; consumiram o artista, o personagem fotógrafo. Ei-las aprendendo com Alice a partir de uma intervenção que pensaram e planejaram com o grupo. Eis o poder da arte em mobilizar a imaginação e a fantasia, em fazer viver a emoção de todos aqueles que com ela se envolvem de alguma forma, conforme expressa o belo excerto de Keats, citado por Manguel (2001, p.288): "Não tenho certeza de nada, a não ser da santidade dos afetos do coração e da verdade da imaginação - o que a imaginação capta como beleza deve ser verdade tenha ou não existido antes" (John Keats, Carta a Benjamin Bailey, 22 de novembro de 1917).
No encontro seguinte à atividade com as fotografias de Salgado, foram apresentadas aos alunos reproduções de obras de Maurits Cornelis Escher, conhecido por seus trabalhos em xilogravuras e litogravuras de obras fantásticas, incomuns, com várias perspectivas, algumas geradoras de ilusão de ótica no apreciador.

Se a fotografia e o ato de se colocar no lugar do fotógrafo mobilizam a imaginação na produção de imagens sobre a realidade e a vivência de emoções sobre o presente, a gravura, nesse caso com a estética fantástica que se aproxima do surrealismo, parece mobilizar a imaginação em direção ao futuro, ao impossível, ao sonhado. Se a fotografia afirma a realidade, a obra fantástica a questiona, a subverte, a revoluciona. Institui, assim, outro tipo de drama - aberto à manipulação da imaginação, enquanto a fotografia impinge-o como única vivência possível.

A produção de Alice, a partir da relação com as obras de Escher parece revelar esse poder da imaginação para produzir outras realidades. Alice aprecia as pinturas de Escher e, desta vez, faz um desenho: uma garota de cabelos vermelhos esvoaçantes está de costas, sentada sobre uma meia esfera que representa o mundo. À sua frente um grande espelho oval, com moldura trabalhada em flores, para o qual ela olha fixamente. Ao lado escreve o que o espelho espelha: o título, "Imenso mundo a conhecer":
Saia da cama, saia do muro, saia do mundo; Você é um universo em constante expansão. Você é capitão desse barco. Navegue os sete mares; Descubra o oitavo. Leia um livro sobre vaidade; Dance sobre as estrelas; Vá à segunda dimensão. Você tem o mundo em suas mãos.

(Ass.: Srta. Sousa.)

6 Segundo Souza \& Andrada (2013, p.362), “... Vigotski (1935/2010), ao se referir ao meio, não o considera como um fator puramente ambiental, mas como movimento relacional entre o interno e o externo que configuraria uma situação sui generis, única, que ele denomina de Situação Social de Desenvolvimento. Para Vigotski (1935/2010), como o sujeito vivencia algo se modifica na medida em que se modificar sua Situação Social de Desenvolvimento". 
Parece possível afirmar, a partir do movimento de Alice na apreciação das produções e na produção de um desenho/história, o que diz John Keats (Manguel, 2001, p.288): "o que a imaginação capta como beleza deve ser verdade - tenha ou não existido antes". A reflexão crítica revestida de desesperança e certo pessimismo em relação a um homem preso no presente, vítima de suas próprias artimanhas, agora dá lugar à fantasia, ao sonho, à esperança, à liberdade - possibilidades de recuperar a humanidade. A imaginação e a fantasia ganham outra dimensão - segunda? terceira? E novamente, as camadas das obras se adensam, condensam, estão prenhes de significação. Cabe a pergunta: o que há na singularidade de Alice, sujeito ator e autor, capaz de mobilizar tantas ideias geniais a partir da apreciação de materialidades artísticas? Projetar-se no espelho em direção a outro mundo, outra dimensão, assumindo outra identidade: a Srta. Sousa. Parece que a estética surrealista é poderosa na produção da fantasia e do poder de agir!

Segundo Vygotski (1931/2006), na adolescência, a forma característica de relação da imaginação com a realidade é mediada pelo pensamento por conceito, caracterizado pela generalização, que tem como central o significado e o sentido. Então se pode afirmar que a imaginação é constituída por imagens, no que concerne a sua estrutura, e por significação, no que concerne a seu conteúdo. Essa significação tem no centro a emoção. Para o autor, o avanço da imaginação na adolescência amplia a experiência do sujeito que consegue perceber fatos e fenômenos que estão além de sua observação direta. Entretanto, é o que Vygotski (1931/2006) denomina de terceiro nível7 de relação da imaginação com a realidade que aqui interessa em especial, visto ter como mediação as emoções, o que a aproxima da Psicologia da Arte.

Para Vygotski (1931/2006), todo sentimento e emoção interferem no modo pelo qual se apreende a realidade, o que significa que os afetos se tornam congruentes com as imagens, impressões e ideias que se têm do mundo. Assim, "quando estamos alegres vemos com olhos totalmente distintos de quando estamos melancólicos" (Vigotski, 1925/1999, p.9, tradução nossa). Para o autor, as bases afetivas são o caminho para a compreensão de como a imaginação é constituída e atua em cada sujeito.

Falando sobre a relação entre imaginação e arte, Souza (2016b, p.84) afirma:

O que é uma obra de arte senão a transformação de uma ideia do artista em uma forma de apresentação que visa tocar os afetos? É a imaginação do artista que está na base de sua produção, ao transformar elementos de sua realidade externa ou interna, experienciada ou imaginada, e expressá-los, conformando-os a determinada linguagem que domina - pintura, poesia, música, fotografia, cinema, teatro. O caráter aberto de produções dessa natureza, ou seja, sua estética também favorecem a imaginação e a criatividade dos sujeitos que com elas interagem, pelo caráter de mediação estética que podem assumir.

Vigotski (1934/2009) fala em fantasia, por vezes utilizada como sinônimo de imaginação, e de seu potencial para aprisionar ou libertar o sujeito de suas condições reais de vida. A esse respeito, Souza (2016b, p.85) ajuda a compreender essa ideia ao aproximá-la da arte:

A dimensão da fantasia que liberta pode ser pensada na relação com a arte, se nos voltarmos para o caráter estético e semântico que a caracterizam, ou seja, sua forma e conteúdo. Quantas vezes nos afastamos da realidade e ficamos imersos na trama de um romance ou ficção que estamos lendo? Ou nos pegamos chorando afetados

\footnotetext{
$\boldsymbol{\nabla} \nabla \boldsymbol{\nabla}$
}

7 Trata-se do nível em que a emoção se enlaça na imaginação, constituindo a significação da realidade. Nas palavras de Souza (2016b, p.84), dessa perspectiva: "todo sentimento e emoção interferem no modo pelo qual apreendemos a realidade, o que significa que nossos afetos se tornam congruentes às imagens, impressões e ideias que temos dela. ... as bases afetivas são o caminho para compreensão como a imaginação é constituída em cada sujeito". 
por uma música cuja melodia e letra nos penetra os sentidos sem pedir licença? Ou, ainda, quando nos damos conta de que não sentimos o tempo passar, de que a tarde se transformou em noite enquanto sofríamos com o herói do filme no cinema ou liberávamos a raiva, mediados pela estética e conteúdo dos personagens malvados?

É possível observar esse movimento nas produções de Alice a partir da apreciação de fotografias e pinturas, com estéticas diferenciadas e conteúdos com significados opostos. Seus afetos são congruentes com as imagens que acessa, fazendo-a viver a tristeza expressa nas fotografias e sucumbir ao padecimento na pele do fotógrafo, ou fazendo-a viver a alegria e possibilidades infinitas expressas nas obras fantásticas, mergulhando na aventura de viajar por um mundo imaginado, sem limites e sem barreiras.

O impacto dessas atividades de que toma parte Alice e seus colegas ainda está sendo analisado, na pesquisa em vias de conclusão. Entretanto, trazer Alice e sua expressão aqui visa oferecer uma pequena evidência do poder da arte na mobilização de afetos e ações do sujeito, ou seja, defender a potência da Psicologia da Arte para promover mudanças em realidades precárias, objetivas e subjetivas, que caracterizam a vida na sociedade contemporânea.

\section{Considerações Finais}

Falando sobre a Psicologia da Arte, Vigotski chama a atenção para o caráter dialético da obra artística, que conteria em si a contradição expressa na relação entre forma e conteúdo. Seria essa contradição inerente a toda obra que faz o sujeito viver, na apreciação estética, sentimentos opostos, e, ao vivê-los, imprime novos sentidos ao que experiência e amplia seus modos de significar e se relacionar com a realidade.

Ainda sobre a contradição que radica na obra de arte, Souza (2016b, p.85) diz que ela resulta da vivência simultânea de emoções e sentimentos opostos, tal como o bem e o mal, que, nos filmes e na literatura, por exemplo, aparecem mais em evidência; do certo e errado, que não necessariamente se opõem, mas se negam; e, ainda, do passado e do futuro, que se negam e se opõem. Ou seja, trata-se de unidades de contrários, cujos elementos constitutivos - no caso dos exemplos, as emoções ou dimensões éticas e temporais - não podem ser acessados simultaneamente na vida cotidiana, mas podem ser vividos e sentidos "a crédito".

Na relação com a arte, essa vivência é possível devido ao tipo de relação que se estabelece com a obra, cujo caráter especular oferece garantias para penetrar a obra sem contudo misturar-se a ela. Essa acepção permite pensar a arte como materialidade que promove o desenvolvimento pela mediação estética e semântica, dimensões potencializadoras de formas mais ampliadas de consciência, de poder de agir e ser no mundo.

Parece que a arte é fonte inesgotável desse tipo de experiência, bastando para tal embrenhar-se em suas intrincadas formas - estética -, e em seus densos e extensos conteúdos - significações, que constituem unidades de contrários. Na obra, pintura, literatura ou música, a estética submete o conteúdo segundo suas leis, e os conteúdos subvertem a estética para que esta consiga expressá-los. Na vida, forma e conteúdo, espaço e tempo, são vividos de forma imperceptível, incompreendida, e as emoções e sentimentos seguem o fluxo da vida cotidiana com seu caráter fragmentado. Eis uma contribuição que a psicologia pode oferecer à conscientização do homem: apropriar-se do que ela tem de arte e lançar mão da rica produção da cultura para cultivar a humanidade.

\section{Colaboradores}

Todos os autores contribuíram igualmente na concepção, desenho, análise, interpretação dos dados, revisão e aprovação da versão final do artigo.

\section{Referências}

Andrada, P. C., \& Souza, V. L. T. (2015). Corpo e docência: a dança circular como promotora do desenvolvimento 
da consciência. Psicologia Escolar e Educacional, 19(2), 359-368. http://dx.doi.org/10.1590/2175-35 39/2015/0192855

Arendt, H. (2014). A condição humana. Rio de Janeiro: Forense Universitária. (Originalmente publicado em 1958).

Charlot, B. (2013). O professor na sociedade contemporânea: um trabalhador da contradição. In M. C. d'Àvilla (Org.), Ser professor na contemporaneidade: desafios, ludicidade e protagonismo (pp.15-36). Curitiba: CRV.

Clot, Y. (2014). Vygotski: a consciência como relação. Psicologia e Sociedade, 26(Esp 2), 124-139. http:// dx.doi.org/10.1590/S0102-71822014000600013

Dugnani, L. A. C., \& Souza, V. L. T. (2016). Psicologia e gestores escolares: mediações estéticas e semióticas promovendo ações coletivas. Estudos de Psicologia (Campinas), 33(2), 247-259. http://dx.doi. org/10.1590/1982-02752016000200007

Dugnani, P. (2017). Métodos de análise de imagem para o desenvolvimento de linguagem visual: revisão integrada. (Relatório de Pesquisa). Recuperado em março 30, 2018, de http://dspace.mackenzie.br/ handle/10899/18746

Escher, M. C. (1938). Day and night. [Litografia]. Museu Escher, Haia.

Escher, M. C. (1953). Relativity ou Casa das Escadas. [Litografia]. Museu Escher, Haia.

Escher, M. C. (1960). Subindo e descendo. [Litografia]. Museu Escher, Haia.

Friedrich, J. (2018). Lev Vigotski: mediação, aprendizagem e desenvolvimento. Campinas: Mercado de Letras.

Heller, A. (1989). O cotidiano e a história. São Paulo: Paz e Terra.

Kandinsky, W. (2015). Do espiritual na arte. São Paulo: Martins Fontes.

Manguel, A. (2001). Lendo imagens: uma história de amor e ódio (5a ed.). São Paulo: Companhia das Letras.

March S., \& Fleer M. (2017). The role of imagination and anticipation in children's emotional development. In M. Fleer, F. González Rey, \& N. Veresov (Eds.), Perezhivanie, emotions and subjectivity: Perspectives in Cultural-Historical Research (Vol. 1, pp.105-127). Singapore: Springer. Retrieved March 24, 2018, from https://link.springer.com/chapter/10.1007/978-98110-4534-9_6\#citeas

Martín-Baró, I. (1997). O papel do psicólogo. Estudos de Psicologia (Natal), 2(1), 7-27. http://dx.doi.org/10. 1590/S1413-294X1997000100002

Neves, M. A. P., \& Souza, V. L. T. (2018). Música e psicologia na escola: mobilizando afetos na classe de recuperação. Psicologia Escolar e Educacional, 22(1), 17-25. http://dx.doi.org/10.1590/2175-3539 2018019065
Petroni, A. P., \& Souza, V. L. T. (2014). Psicólogo escolar e equipe gestora: tensões e contradições de uma parceria. Psicologia: Ciência e Profissão, 34(2), 444459. http://dx.doi.org/10.1590/1982-3703000372013

Petrovski, A. V. (1984). Personalidad, actividad y colectividad. Buenos Aires: Cartago.

Placco, V. M. N. S., \& Souza, V. L. T. (2012). Desafios ao coordenador pedagógico no trabalho coletivo da escola: intervenção ou prevenção? In V. M. N. S. Placco \& L. S. Almeida (Orgs.), O coordenador pedagógico e os desafios da educação (4a ed., pp.25-36). São Paulo: Loyola.

Rosa, G. (2001). O espelho. In G. Rosa. Pequenas histórias (pp.94-100). Rio de Janeiro: Nova Fronteira. (Originalmente publicado em 1962).

Salgado, S. (1996). Trabalhadores. São Paulo: Companhia das Letras.

Salgado, S. (1997). Terra. São Paulo: Companhia das Letras.

Salgado, S. (1999). Outras Américas. São Paulo: Companhia das Letras.

Salgado, S. (2000). Exxodos. São Paulo: Companhia das Letras.

Salgado, S. (2007). África. Colônia: Taschen.

Salgado, S. (2013). Gênesis. Colônia: Taschen.

Sawaia, B. B. (2009). Psicologia e desigualdade social: uma reflexão sobre liberdade e transformação social. Psicologia \& Sociedade, 21(3), 364-372. http://dx.doi. org/10.1590/S0102-71822009000300010

Souza, V. L. T. (1998). Olhares e dizeres revelando a identidade de professoras: refletindo sobre a formação docente (Dissertação de mestrado não-publicada). Pontifícia Universidade Católica de São Paulo.

Souza, V. L. T. (2016a). Contribuições da Psicologia à compreensão do desenvolvimento e da aprendizagem. In V. L. T. Souza, A. P. Petroni, \& P. C. de Andrada (Orgs.), A psicologia da arte e a promoção do desenvolvimento e da aprendizagem (pp.11-28). São Paulo: Edições Loyola.

Souza, V. L. T. (2016b). Arte, imaginação e desenvolvimento humano: aportes à atuação do Psicólogo na escola. In M. V. Dazzani \& V. L. T. Souza (Orgs.), Psicologia escolar crítica: teoria e prática nos contextos educacionais (pp.77-94). Campinas: Alínea.

Souza, V. L. T., \& Andrada, P. C. (2013). Contribuições de Vigotski para a compreensão do psiquismo. Estudos de Psicologia (Campinas), 30(3), 355-365. http://dx.doi. org/10.1590/S0103-166X2013000300005

Souza, V. L. T., Dugnani, L. A. C., Barbosa, E. T., Jesus, J. S., \& Neves, M. A. P. (2016). As mediações estéticas como estratégia de atuação do psicólogo em classes de recuperação. In M. V. Dazzani \& V. L. T. Souza (Orgs.), Psicologia escolar crítica: teoria e prática nos contextos educacionais (pp.205-220). Campinas: Alínea. 
Souza, V. L. T., Dugnani, L. A. C., Petroni, A. P., \& Andrada, P. C. (2015). A síntese como registro reflexivo no trabalho do psicólogo escolar com gestores. Psicologia da Educação, (41), 83-94. http://dx.doi. org/10.5935/2175-3520.20150016

Spinoza, B. (1989). Ética II (4a ed.). São Paulo: Nova Cultural. (Originalmente publicado em 1677).

Vigotski, L. S. (1999). Psicologia da arte. São Paulo: Martins Fontes. (Originalmente publicado em 1925).

Vigotski, L. S. (2009). A construção do pensamento e da linguagem. São Paulo: WMF Martins Fontes. (Originalmente publicado em 1934).

Vigotsky, L. S. (2009). La Imaginacion y el arte en la infancia. Madrid: Akal. (Originalmente publicado en 1930).

Vygotski, L. S. (1991). El significado histórico de la crisis de la Psicología. In L. S. Vygotski, Obras escogidas: problemas teóricos y metodológicos de la Psicología (Vol. 1, pp.257-407). Madrid: Visor. (Originalmente publicado en 1927).

Vygotski, L. S. (1995). Dominio de la propia conducta. In L. S. Vygotski, Obras escogidas: historia del desarrollo de las funciones psíquicas superiores (2a ed., Vol. 3, pp.285-302). Madrid: Visor. (Originalmente publicado en 1931).

Vygotski, L. S. (2006). El desarollo del pensamento del adolescente y la formación de conceptos. In L. S. Vygotski, Obras escogidas: paidologia infantil (Vol. 4, pp.11-46). Madrid: A. Machado Libros. (Originalmente publicado en 1931).

Recebido: abril 24, 2018

Versão final: junho 12, 2018

Aprovado: agosto 17, 2018 